\title{
Electrochemiluminescence Unit
}

National Cancer Institute

\section{Source}

National Cancer Institute. Electrochemiluminescence Unit. NCI Thesaurus. Code C161491.

A unit for measuring concentration or/and reactivity of a test substance as defined in the literature reference standard for the particular quantitative electrochemiluminescent method. 